\title{
PAR'T III.
}

\section{MEDICAL MISCELLANY.}

Keports, Transactions, and Scientific Intelligence.

\section{ROYAL ACADEMY OF MEDICINE IN IRELAND.}

\author{
President-Sir Charles Ball, F.R.C.S.I. \\ General Secretary_James Craig, M.D., F.R.C.P.I.
}

\author{
SECTION OF SURGERY. \\ President-J. Lentaigne, P.R.C.S.I. \\ Sectional Secretary-A. J. Blayney, F.R.C.S.I. \\ Friday, March 11, 1910. \\ DR. STOKES in the Chair. \\ Unusual Fracture of the Tibia and Fibula.
}

Mr. W. S. Haughton read a paper on a case of fracture of the tibia and fibula, treated by screw-plating. A lad of sixteen years fell through the floor of a mill, and, alighting on one foot, fractured both bones of the leg transversely some two inches above the ankle-joint. Total eversion of the foot was produced, so that the sole looked upwards. All justifiable efforts at reduction and treatment in plaster of Paris proved ineffectual, as shown by X-ray examination, so a screwing operation was done. Steel plates were specially made to measure on the skiagrams, and one was applied to each bone, that on the tibia being $\mathrm{Y}$-shaped. $\mathrm{He}$ (Mr. Haughton) alluded to the points of general interest in the modern operative methods of treating fractures, laying special stress on two-(1) The desirability of using every reasonable effort to reduce fractures before advising operation, testing the result in every 
case by X-rays; (2) the absolute necessity of preserving strict asepsis throughout operation by keeping screws, plates, drills, screw-driver, \&c., boiling all the time in the steriliser till the moment for using same. The features of special interest were then alluded to, and demonstrated by means of stereoscopic skiagrams. The boy walked well, and the result was good.

Mr. A. J. Blayney said the case added another to the series showing the excellent results now obtained by the operative treatment of fractures. But he thought there was a slight tendency to regard every fracture as being necessarily treated by operation, and there were some things still to be said in favour of the treatment of fracture without operation. There was a considerable number of cases in which it was possible to obtain and keep reduction without the use of any mechanical appliances further than external apparatus, and the absence of pain observed after operative measures could also be obtained without operation. In cases, however, like that before them, and in fractures of the femur, there was no doubt the use of splints would not give anything like satisfactory results. On the question of interference with the growth of the bone, if growth continued, a certain amount of longitudinal strain would come, and he was inclined to think that the boy would be better without the plate.

Dr. Stevisson thought Mr. Haughton had hardly laid sufficient stress on the way in which, with an X-ray photograph, it was possible to estimate with accuracy where to make the incision and where to find the fragments with the least delay. He had assisted at the operation, and before Mr. Haughton cut the skin at all he was able to show the position in which the plates were to go.

DR. STOKEs asked for some more information on the making of the holes in the shaft of the bone at right angles, also as to the way in which the foot was inverted. He did not see why the screw in the epiphysis should give any trouble.

Mr. Haughton, in reply, said he would consider the taking out of the $\mathrm{Y}$-shaped plate if pain occurred, and the $\mathrm{X}$-rays showed evidence of rarefying osteitis; but he believed that if growth took place it would be very slow, and the pressure on the bone would cause an absorption which would allow the screw to pass upward, and a corresponding deposit of bone would occur on the opposite side. When dealing with a triangular bone by wire, if they put two wires parallel they would have a hinge in which 
bending displacements were possible, while lateral displacements were not possible; some slight torsion displacement was also possible. To check that they should have at least two wires passing through the bone transversely, which would give greater rigidity than if the wires were parallel. He did not know in what position the foot struck the ground, but the sole was turned upwards through $180^{\circ}$.

\section{$A$ Case of Thrombosis of the Lateral Sinus with Resection of the Jugular Vein.}

Mr. O. Gogarty reported this case in order to show the importance of considering the possible presence of disease of the middle ear in the diagnosis of obscure cases. The patient had been supposed to be suffering from gastric disturbance when vomiting was marked, and later from stone in the kidney when great hæmaturia occurred, and did not seek admission to hospital until the disease had been present for six days. Temperature on two occasions had been $105^{\circ}$, and rigors had occurred before admission. The prominent feature of the case was the total absence of localising signs. Edema over mastoid, Griesinger's sign, tenderness over jugular cord, and stiffness of the neck were missing; though the presence of pyæmia made the case all but hopeless, it was decided to give the very slender chance of recovery by operation. A clot nearly two inches in length was removed from the lateral sinus after a considerable portion of the internal jugular vein had been resected. The patient lived only two days, dying of pyæmia, with a rash and well marked jaundice.

Dr. DeMPSey said they should be grateful to Mr. Gogarty for showing a case which was not an operative success. Lateral sinus. thrombosis was much more commonly met with since the radical mastoid operation had come into vogue. The great difficulty was the question of diagnosis in certain cases, and in dealing with such he thought they should be guided by what they met with when treating the case. He had seen a case in which the diagnosis was ty phoid fever that developed some discharge from the ears. He cut down on the mastoid, and found extensive bone disease. He did the ordinary operation, and the patient was much better for several days. Then came a temperature of $105^{\circ}$ and sharp rigor, suggesting lateral sinus disease. He reopened, but found things as at first. The same symptoms recurred for three weeks about 
four times a week, but further operation was refused, and yet the patient got steadily well, and was now in perfect health. In another case, in which the radical mastoid operation was performed, the patient also developed a high temperature and rigor. The lateral sinus was exposed, and showed a surface greyish, and breaking down, with the emission of pus. The jugular vein was tied in the neck, and the sinus was freely opened with free hæmorrhage. The patient died, and the trouble was found to be a cerebellar abscess. If one met with a vein clotted down in the neck, it should be cut down on and the vein excised; but if one found the sinus filled with clot in the region of the mastoid, the question grose as to whether the internal jugular should be tied at all or not. Opinions were about equally divided. Cases in which it was not tied had done just as well as if the ligature had been effected. But the test was hardly a fair one, as the cases of tying were practically desperate cases which were given a last chance.

Dr. Harvey sympathised with Mr. Gogarty in his brave endeavour to save the patient's life, but the patient had been infected several days before the operation, and the diagnosis was very difficult. Mr. Gogarty's procedure was very wise, and he would like to know what were the indications as to when the internal jugular should be opened.

Mr. W. S. Haughton said it was from such cases very often that they learned most. He had operated on five cases of suspected thrombosis, in three of which the condition was found, and death followed. In the other cases there was no apparent thrombosis, and death followed. He did not ligature the internal jugular, but he was inclined to think it should be done oftener than it had been done. In a case which was not septic, he adopted a trephine opening, and cut into the lateral sinus. Severe hæmorrhage followed, and he was obliged to plug. Six days later he reopened and removed the plug, and no hæmorrhage followed. He had, however, given up the trephine, as he found the broad gouge did the work more safely.

Mr. WM. TAYLOR said he had seen the swelling which was found along the jugular vein to be due, not to an infection of the vein, or thickening, or clot, but to an infection of the glands. Where they could easily recognise on palpation the cord-like swelling described in the books, it was too late; but there was one chance in five hundred which should be given to the patient. 
Where there was the smallest suspicion of any intra-cranial complication, operative interference should be undertaken at an early stage. In the combination of two intra-cranial complications due to ear disease, the difficulty of diagnosis was greatest, and he believed that septic sinus infection predominated. He had seen a case in which the phenomena of cerebellar trouble did not manifest themselves until some twenty-four or thirty-six hours after the lateral sinus had been opened. Cases of sinus. infection, where there was not a clot, were, he felt, far more dangerous than those in which there was, and he would be inclined to ligature the jugular, even though the infection might be carried by other channels. He would have no hesitation in doing so where there was clear evidence that the sinus was infected; where there was a doubt, he would expose the mastoid and the lateral sinus, and deal with the condition as he found it.

Mr. Pearson asked what were the indications for operating: on obvious ear cases, where pus was found under tension in the mastoid without any definite evidence of other complication at the time. He recalled a case in which the radical mastoid operation. was done. After the operation the patient appeared to be very well, but temperature rose later to $103^{\circ}$, and a blood-count showed a marked leucocytosis. The patient became very dull, and answered questions slowly, but there were no other symptoms. The patient was reopened, and a large temporo-sphenoidal abscess. was found with pus under very high tension. He felt certain the abscess was present at the first operation, but that it had passed the stage at which it gave the symptoms for which they were on the look-out.

Mr. Gogarty, in reply, referred to the question as to when the jugular vein should be resected in the case of thrombosis of the lateral sinus. In his opinion, although he knew that many thrombi had been successfully removed without ligaturing or resecting the vein beforehand, it was better to ligature the vein if it was decided to open the sinus when the surrounding parts were septic; and to resect the vein in case of thrombosis of the jugular bulb, or whenever it seemed probable that the vessel wall might be itself a carrier of infection. 


\section{SECTION OF OBSTETRICS. \\ President-Henry Jellett, M.D., F.R.C.P.I. \\ Sectional Secretary-Gibion FitzGibBon, M.D., F.R.C.P.I.}

Friday, April 1, 1910.

The President in the Chair.

Ruptured Ovarian Gestation.

The following Communication from the Committee of Reference was received :-

Dr. RowLETrE said the specimen consists of an oval blood-clot, three inches long in diameter, to which is adherent a small piece of tissue, partially embedded in clot. The outer surface of the clot is laminated, and the coats peel off readily. On cutting. through the specimen, the tissue is found to be tough, greyishpink in colour. Between it and the clot is a bright yellow band, one inch long by three-eighth inch broad, obviously the wall of a ruptured corpus luteum* in which the clot must have formed.

Microscopically.-The grey tissue is ovarian tissue, with a partial covering of peritoneum; the yellow band consists of typical lutein cells; in the clot near the yellow band are numerous chorionic villi. No embryo was discovered.

The specimen is one of pregnancy, the ovum having developed in a Graafian follicle.

"We have examined the specimen described by Dr. Rowlette in the accompanying manuscript, and are of opinion that the case is one of ruptured ovarian gestation. The possibility of its having been tubal or tubo-ovarian is excluded by the fact that the tube was found to be normal and separate from the ovary at the operation. From the close relation of the foetal structures to the lutein cells, it appears probable that the impregnation took place in a Graafian follicle, from which the corpus luteum subsequently developed.-H. C. EARL, A. C. O'Sullivan, H. JELLETT."

(a) Sarcoma of Body of Uterus.

(b) Carcinoma of Body of Uterus.

Dr. JELLETT exhibited specimens of the above by way of contrast. The patient in the first case was a girl, aged twenty. 
Her symptoms were frequent and heavy menstruation, and a considerable amount of leucorrhoea almost entirely of pure pus. Examination showed the uterus to be considerably enlarged and very nodular. He passed a Bozeman's catheter and washed away a considerable amount of pus situated at the upper part of the uterus. The diagnosis was apparently myoma, but he thought it might possibly be a case of sarcoma. As against myoma was the age of the girl. The operation presented no particular features. He did a supravaginal hysterectomy, leaving a portion of the cervix. There was a tumour in the right broad ligament lying between the hilum of the ovary and the uterus. After removal the condition of the endometrium as shown in the specimen was plain to be seen. There was enormous proliferation apparently of mucous membrane all over the upper surface, and on the posterior wall a nodule almost like a myoma which had lost its blood supply. On examination it was proved to be sarcomatous. The uterine wall was extraordinarily thick. At first sight the specimen gave one the impression of recent parturition. A section through the uterine wall showed nothing but muscular tissue, and he did not know how to explain the thickening. The patient made an excellent recovery. He had not removed the remainder of the cervix, as the malignant growth was entirely separated from it by an inch and a half of tissue.

The second specimen was from a woman, aged about fifty-five or sixty years. She had gone into hospital complaining of profuse discharge. He found a large uterus, also nodular. $\mathrm{He}$ washed out the uterus and found great retention of pus. On scraping with a blunt curette he brought away a lot of sloughing growth. The scrapings were carcinomatous. On opening the abdomen he found the uterus comparatively free. There was very little extension of the growth in the neighbourhood of the cervix, and the fundus was entirely free. But on the left side there was a growth extending up into the pelvic glands behind the peritoneum. This he thought he was able to extirpate. On the other side there was a similar extension. The glands all along the aorta were enlarged. He removed them to the level of the second lumbar vertebra. He removed the uterus and a good deal of the vagina. The uterus lay low in the pelvis, and when he cut across the vagina he was within an inch of the vulva. The condition of the patient after the operation was fairly satisfactory, and he thought he would try to take away another gland 
higher up. He split the peritoneum further along the ureter, and found the remaining gland firmly adherent to the lower vena cava. The patient gradually got weaker, and died in a couple of days. The case was one of long standing, and he thought her heart muscle was weak. There were no obvious symptoms of sepsis.

Dr. Purtfoy said the case of sarcoma was, in his experience, quite without parallel. He would watch for the subsequent history of the case, as he himself had had a patient aged sixty-five who died of secondary disease in the left lung a few months after he had removed a large fibrous uterus, which for thirty years had caused inconvenience only by its size. He did not remove the cervix. With regard to the second case, it was admitted that a proportion of the enlarged and hardened glands, the appearance of which suggested malignant disease, did not really contain it. Nevertheless, any of them who had such a case would, no doubt, endeavour to remove the glands as completely as possible. In the case of an aged patient, they had to consider whether they were warranted in carrying out a prolonged operation for the complete removal of all the enlarged glands they could feel.

DR. JelletT, remarked that Sir William Sinclair, on his recent visit, had said to him that he was in the habit of telling his class that cancer of the body of the uterus occurred only in comparatively well-to-do cases, and cancer of the cervix in very poor patients. Sir William's idea was that the only way to prevent cancer of the cervix was by improving the conditions under which the patients lived. In his (the speaker's) experience the rule did not apply in Ireland.

Dr. Holmes said that, looking back on the cases in the Rotunda, the number in the extern dispensary of cervical cancer seemed to him to be more numerous than the house cases. Neglect of discharges might set up disease, but the upper classes, if anything went wrong, generally had the matter seen to.

Dr. Purefoy said his experience did not correspond with Sir William Sinclair's. He would like to know if, from inspection of the sections, it was possible to determine whether the sarcoma had occurred in the connective tissue or muscular cells.

Dr. Jellett said that there was a doubt in the mind of Prof. O'Sullivan, who reported on the specimen, as to its origin in the ovary. Prof. O'Sullivan's report is as follows :-

"The uterus was large, the body being four inches in length 
and the wall a little over an inch thick at the thickest part. The upper two-thirds of the cavity were filled by an irregular growth, with numerous polypoid excrescences projecting into the lumen. The surface of the growth was acutely inflamed and partially necrosed, and covered in places with a thick layer of pus, which contained a variety of organisms-bacilli and cocci. The growth could be seen to infiltrate the posterior wall of the uterus, and secondary nodules could be felt in the upper and posterior part of the wall. The ligament of the ovary was also infiltrated, and the ovary itself was converted into a mass, partly nodular and partly cystic. Under the microscope the tumour showed a very cellular structure, spindle and large round cells with numerous. nuclear figures. The solid tumours in the ovary had a similar structure. A large nodule lay in the upper uterine wall, which was of a dull grey colour on section, and proved to be of similar structure."

\section{Suppurating Uvarian Cyst with Tubercular Pyosalpinx.}

Dr. FitzGibion exhibited this specimen. A girl, B. N., aged nineteen, had four years ago tubercular disease of a finger, which was amputated. Her menses, which had always been regular from the time they commenced, ceased in November, 1909, and shortly after that she developed a cough, and had several attacks of vomiting, accompanied by pain in the abdomen. She was admitted to Mercer's Hospital on January 3, 1910, and the speaker first saw her about the end of January. She then had an irregular temperature, varying between $99^{\circ}$ and $101^{\circ}$, and pulse from 95 to 110 . She had ceased to vomit, but complained of acute pain in the abdomen, and was very constipated. A tumour could be felt extending to one and a half inches from the umbilicus. On vaginal examination the pelvis was found to be filled up by a cystic tumour, which was fixed, and which pushed the uterus upwards and forwards. The left appendages could be felt apparently normal, but the tumour prevented any examination of the right side of the pelvis. The patient was kept in bed and the bowels were freely.acted upon, and then the temperature improved, but the pain continued to be severe. On March lst the abdomen was opened, and an ovarian cyst was found springing from the right side and firmly adherent all over the back of the pelvis. The intestines were completely shut off by the omentum. In freeing the cyst from the pelvis it ruptured, and discharged 
about two pints of purulent contents. The left tube was greatly thickened and adherent, also containing pus. By working down the left side of the uterus and then dividing through the vagina the right appendages were shelled out. The left tube which was removed was perfectly normal, and the left ovary was retained in situ, as it seemed quite healthy. The pelvis was drained through the vagina with iodoform gauze passed from above down, and only iodine catgut was used throughout. Cultures were made from the pus in the tube immediately after the operation with a view to making an autogenous vaccine if the case developed into one of acute sepsis, as was anticipated from the amount of pus which unavoidably got about the pelvis; also saline enemata, two pints, were given every two hours for two days. The temperature rose after the operation to $102^{\circ}-103^{\circ}$, and the pulse to 130 to 140 , and remained fairly steady for the first four days, when they began to improve, and have since remained from $99^{\circ}$ to $101^{\circ}$ and 100 to 120 . The lower inch of the abdominal wound opened and discharged a foul-smelling pus for about ten days, and is now granulating, while the pus from the vagina went through the same stages. The patient looks better, is free from pain, but continues the high temperature and pulse. The report received on the specimen was that the cultures contained no pyogenic organism, and except a bacillus which resembled $B$. coli the pus did not show any other pyogenic organisms. Sections made from the wall of the ovarian cyst proved to be tubercular, while the left tube was normal. The ovarian tumour showed a large single cavity, strongly suggestive of an abscess, and in no way resembling an ovarian cystoma.

Dr. Purefoy said he understood there was no evidence of gross uterine disease, and the removal of the uterus did not commend itself to him as the best proceeding under the circumstance. It inereased the area in which infection might take place, and it was a serious loss to a patient at the age of the case. He thought an adequate opening might have been found in Douglas's space.

Dr. Rowlette said the association of tuberculosis and cystic growth in the same ovary was, he thought, very rare, though one saw frequently tuberculosis of the tube associated with a certain kind of cystic growth of the ovary. It was indeed rare for any tumour to become infected by tuberculosis. He thought the cyst was really an abscess cavity.

With regard to the President's specimen, it seemed 
to him to be an advanced case of sarcoma starting in the endometrium. He should say the nodule was sarcoma from the beginning. The fact that the uterus was so large showed, he thought, a good deal of resistance on the part of the patient, and that the growth was not very rapid. The fibrosis must have been a reaction to the growth of the tumour, which would be encapsuled to a certain extent.

Dr. Jelletr, speaking on Dr. FitzGibbon's specimen, said he had never before heard of a specimen of tuberculosis of an ovarian cyst, and the first thing to know was the nature of the cyst. If it was purely an abscess starting in the ovary, then the tubercular infection would not be quite so unusual. But, if it was a proliferating cyst of the ovary, he did not know that he had ever heard of such a condition being recorded before, and he thought Dr. FitzGibbon should be asked to give them some further information at a later date.

Dr. FitzGibron, in reply, said the section showed typical tubercular infection, but he did not think any one could say definitely that it was from a proliferating ovarian cyst, in fact the inner surface of the section did not show anything to suggest ovarian cystoma, but strongly resembled the lining of an abscess cavity. He thought the case, now that he had obtained and seen a section of the tumour, was one of tubercular ovarian abscess. In reply to Dr. Purefoy, he said the condition of the patient appeared so bad, and such a quantity of pus had escaped about the pelvis, that he thought the only chance was to obtain absolutely free drainage, and that this would be best by removal of the uterus, even then he hardly expected the patient to survive.

Our Responsibilities in the Prevention of Inherited Syphilis.

Dr. Spencer Sheill read a paper on the above subject. It is published in full at page 15 .

Dr. FitzGibion agreed with the statement as regards syphilitic infants being born perfectly healthy. It was still very undecided as to when infected people were free from the infection, as close examination might show that persons who were supposed to be undergoing continuous medication had missed a large number of doses. The old method of giving drugs by the mouth necessitated great trust in the patient, but the present method of injection enabled one to tell whether the patient had kept up the treatment. 
Dr. Solomons said there was a baby born in the Rotunda that evening whose mother had had two six-month babies before, and there was a definite history of her having contracted syphilis from the husband. At the beginning of the present pregnancy she came into hospital and started a course of mercury and potassium iodide. She took it regularly in fluid form, and the baby was quite healthy and strong.

Dr. Seymour Stritcr said they could not lay down a fixed date, in acquired syphilis, for permitting marriage in both sexes. It was generally taken that man could not infect the ovum after six years, whether he had treatment or not, but woman, he thought, might do it as long as she was capable of childbearing. Ordinarily syphilologists did not like to let the innocent parent know of the condition, as it set up disunion in the family, but they must use discretion. Opinion was divided as to whether a man could infect the ovum at all, as the spirochætæ are supposed to be too large to be carried in the sperm. Some believe that spores, or some resting stage of the spirochæte might be so conveyed, should such conditions be discovered in the life history of the specific organism.

Dr. Pugin Mendon thought the father always infected the mother first without directly infecting the fotus. The time for the development of congenital syphilis varied very considerably: he had seen a child which was healthy for fifteen years. He did not think the form in which the mercury was taken mattered, but it was important to see that the mercury was absorbed and really passing through the system by periodic examination of the urine.

Dr. Rowlette said it was extremely difficult to say that a child was free from syphilis. If one searched for the spirochæte he thought there was no doubt it would be present in great numbers in the liver in cases of congenital syphilis, but the pathologist was not often asked to make such an examination: he was usually asked only to look for gross signs, which might not be at all distinctive. The gross sign on which he relied most was the change that took place in the line between the cartilage and the bone at the end of the long bones, particularly at the lower end of the femur. If one opened the knee-joint and split the bone, one found a very distinct broad white or yellowish band if syphilis were present, inflammatory in origin probably, the cartilage and the bone infiltrating each other. 
In the healthy child there was a perfectly clean line. But in some cases of congenital syphilis that sign was not present. Generally the liver was enlarged in congenital syphilis; but in some cases it was found shrunken and very small, and with a large and strong fibrous capsule. While the positive diagnosis of syphilis could sometimes be readily made, it was much more difficult to make a negative diagnosis without definite examination for the spirochæte.

Dr. Purefoy said he had ceased to make inquiries from parents as regards syphilis, as the truth was not likely to be told, and he thought it was better to be guided by the clinical history of the case, and to give mercury guardedly. In such cases it was important to be quite clear that there was no kidney disease. He thought the old-fashioned "snuffes" was generally fairly good evidence of congenital syphilis. A very interesting evidence of congenital syphilis was the form of pemphigus which developed on the palms and soles of the feet of syphilitic infants in the first three months.

Dr. JeLletr thought that if one wanted to secure the greatest possible immunity to the ovum one should treat both father and mother. There were a number of conditions that appeared to occur more frequently in syphilitics than in others, such as malformations in which there might or might not be obvious syphilis. Might there not be some disease of the ovum transmitted from the father, some consequence of syphilis, that might be transmitted to the ovum independently of the presence of the spirochæte? It seemed to him that the fotal liver was always so large in comparison with the size of the infant that a very great increase of size would be needed in order to appreciate the fuct that it was morbidly enlarged.

DR. SHEILL, in reply, said he had not noticed any undue proportion between the wejght of the fœtus and placenta. He believed it was quite possible to become able to recognise during life in a certain proportion of cases a decided enlargement of the liver in syphilitic infants. He thought it was quite possible for syphilis to be transmitted from the father to the ovum without any demonstrable lesion on the part of the father. Unless the father had an open sore, he did not see how he could first infect the mother, as Dr. Meldon had said. Of course the sperm, if sufficiently large to contain one of the organisms, might first infect the mother 
presumably through the mucous membrane, and she might infect the ovum through her own system. But if the sperm was able to carry one of the organisms at all, it was much more likely to go directly to the ovum. If mercury was pushed to the point of salivation, he did not think it was necessary to test the urine. He thought it was a gross injustice to a child if one or other of the parents was not informed of the state of affairs. In later years there might be many effects, and a confession to the doctor might save the child from severe constitutional trouble by wrong treatment. Dr. Solomons had better wait a while to be sure that the child born that evening was really free or not. As regards the administration of drugs, injections were very much better from the therapeutic point of view, but tabloids were easier to take secretly. They should adopt the most efficient form for the particular patient.

Dr. StritCh remarked that the infection might be carried by the seminal fluid.

\section{Parturition Depressed Fracture of Parietal Bone.}

DR. Solomons showed, for the Master of the Rotunda Hospital, a specimen of a fractured skull which had been raised by means of one blade of an American bullet forceps. He said that the case occurred in a quartipara, who gave a history of her previous babies having had "dents" in their heads. Her pelvic measurements were-interspinous, $27 \mathrm{~cm}$. ; intercostal, $28 \frac{1}{2} \mathrm{~cm}$; external conjugate, $17 \mathrm{~cm}$; conjugata vera, $6 \frac{1}{5} \mathrm{~cm}$., transverse of inlet, $13 \frac{3}{10} \mathrm{~cm}$. Prolapse of the cord occurred when the membranes ruptured, and version was performed and the child delivered. When born it was found that there was a depressed fracture of the right parietal bone. This was raised as follows:-The point of a sharp bullet forceps was placed in the centre of the depression, the forceps was turned through a right angle, and then raised; it was easily to be seen in the specimen that the cure of the fracture was complete. This method, which was first performed by Dr. Tweedy, had been carried on in the Rotunda Hospital with uniform success. In this case the infant became jaundiced soon after birth, and died on the third day. There was no paralysis. A post-mortem examination revealed nothing except the mark of the bullet forceps in the brain to the extent of possibly one-eighth of an inch, and evidently this had nothing whatever to do with the death of the child. 
Dr. Neill said he had seen a deep dent in a child which was born alive, and spontaneously recovered without interference.

Dr. Jelletr asked if it was the practice to lift all dents. with bullet forceps.

Dr. Pearson said the skull of a new-born child was a very pliable structure, and might not require any treatment to elevate a fracture. From a surgical point of view the objection which he saw was the possibility of injuring a meningeal vessel.

Dr. Holmes thought any noticeable depression ought to be raised. He had used the method several times, and the children did very well.

Dr. FitzGrbbon said there was a hæmatoma between the dura mater and the parietal bone, not very extensive, and he asked if the bullet forceps had punctured the dura mater.

Dr. Solomons, in reply, said all depressions of any import were raised. There was a puncture in the dura mater when the specimen was fresh.

\section{LITERARY INTELLIGENCE.}

Much interest is sure to be aroused by the announcement of a new book by Dr. Berry Hart, of Edinburgh, entitled "Some Phases of Evolution and Heredity," which Messrs. Rebman, Ltd., will issue very shortly. In the work the chief mechanism of evolution-namely, Darwinism, Weismannism, and also Mnemismare critically considered in modern lights. Mendelism is especially gone into, and a new scheme as to Mendel's crossing experiments is suggested. It seems to clear up some of the difficulties. A new theory of evolution and its transmission is described, showing that probably these two processes are intrinsic and not effected by outside conditions so much as is generally held, and that Biometric work must take a high place in future in these questions. In the remaining chapters the questions of the bearing of modern views and those of Heredity, \&c., are briefly taken up. Bee life in the light of evolution, and especially in the Observation Hive, is considered and illustrated. 